\title{
Perspectivas acerca do conceito de (In)consciente: o mundo dos botões
}

Perspectives about the concept of (un) conscious: the world of buttons

Perspectivas sobre el concepto de (In) consciente: el mundo de los botones

Valdecir de Godoy Borges ${ }^{1 *}$, Ana Maria de Almeida Alves².

\section{RESUMO}

Objetivo: expôr a discussão acerca de conceitos propostos pela Filosofia, Psicanálise e Sociologia, com fundamento em uma leitura geral, em perspectivas de autores que abordam o consciente e inconsciente, bem como o consciente coletivo. Revisão Bibliográfica: temática em estudo apresenta complexidade e dispersividade, que permitem justificar esta abordagem generalista propiciando outro enfoque conceitual, e discorrendo por perspectivas que vários autores apresentam perante o entendimento de que não há uma univocidade do conceito de consciência, o texto discorre com base nas perspectivas de diversos estudiosos e em como estes apresentam os conceitos de consciente e inconsciente. Considerações Finais: as considerações expostas, ao longo do texto, permitem expor o diálogo que ocorre entre várias áreas, em interações que propiciam demonstrar como a Psicanálise tem ampla relação com a Filosofia e a Sociologia, não se desvinculando de conceitos que são muito próximos.

Palavras-chave: Consciência. Inconsciente. Teorias.

\begin{abstract}
Objective: to expose discussion about the concepts proposed by the Philosophy, Psychoanalysis and Sociology, based on a general reading, in perspectives of authors who deal with the conscious and unconscious, as well as the collective conscious. Bibliografic Review: the theme in this study introduces complexity and dispersity, which allow to justify this generalist approach, with another conceptual approach, but explaining through perspectives that various authors present faced with the understanding that there is not a univocal concept of consciousness, the text deals with the basis of the perspectives of many scholars and how they present the consciousness. Conclusion: the considerations set out along the text, allow to expose the dialog that occurs among several areas, in interactions that provide to demonstrate how psychoanalysis have extensive relationship with the philosophy and sociology, not disconnecting from concepts that are very close.
\end{abstract}

Key words: Consciousness. Unconscious. Theories.

\section{RESUMEN}

Objetivo: describir una discusión basada en la lectura general de conceptos propuestos por la Filosofía, el Psicoanálisis y la Sociología, según la óptica de autores que abordan el consciente y el inconsciente, así

\footnotetext{
${ }^{1}$ Albert Einstein, Universidade Municipal de São Caetano do Sul (USCS) - Campus Bela Vista - São Paulo.

*E-mail: marxboetila@gmail.com

2 Centro Universitário Nove de Julho - São Paulo.
}

SUBMETIDO EM: $8 / 2019$

ACEITO EM: 9/2019

PUBLICADO EM: 11/2019 
como también el consciente colectivo. Revisión Bibliográfica: la temática en estudio presenta complejidad y dispersividad, justificando el abordaje generalista que discurre entre las perspectivas presentadas por diversos autores. delante del entendimiento que no existe univocidad del concepto de conciencia, el texto trata sobre la manera en que los autores presentan el consciente y el inconsciente. Conclusión: Las consideraciones expuestas favorecen el diálogo entre varias áreas, con interacciones que propician demostrar la gran relación que tiene el psicoanálisis con la filosofía y la sociología, sin desvincularse de los conceptos próximos que comparten entre ellos.

Palabras clave: Consciencia. Inconsciente. Teorías

\section{INTRODUÇÃO}

A esfera de conteúdos e de estados conscientes ou inconscientes nem sempre se considerou como objeto adequado para a pesquisa, por envolver conceitos por demais abstratos, mas ao longo dos últimos séculos a Ciência propiciou avanços acerca da mente e seu funcionamento e sobre a consciência apenas como argumento de especulação filosófica ou psicanalítica para adquirir uma maior base também na perspectiva fisiológica, em entendimento dos estados mentais com as atividades do ser humano e as relações sociais destes indivíduos (PRUDENTE RCAC; RIBEIRO MAC, 2005).

Dentro desta perspectiva, a discussão exposta surge em um contexto de modernidade sem prescindir da exposição da evolução do pensamento filosófico antecedente, especialmente, em face do entendimento da existência da complexidade temática que é também dispersiva, sendo importante expor que a temática que discorre acerca do inconsciente, consciente e consciente coletivo é complexa por se tratar de um espaço transdisciplinar, envolvendo assim perspectivas que decorrem da visão da Filosofia, da Sociologia, bem como da Psicanálise em um conjunto que se apresenta capaz de propiciar consenso (GOMES G, 2007).

De acordo com Garcia-Roza LA (2009), o termo inconsciente ao ser empregado, em tempo anterior aos registros e estudos de Freud, era entendido como de forma puramente adjetiva para designar aquilo que não era consciente, mas não se entendia ainda como termo designativo para o sistema psíquico distinto dos demais e dotado de atividade própria. A noção de inconsciente, nesse sentido, não designava nada de importante ou de decisivo que pudesse ser aplicado paa a compreensão da subjetividade como se verificou posteriormente.

Complementa-se que o inconsciente não é algo que se verifica abaixo da consciência, mas um sistema psíquico que não se mostra, mas que decorre de contraposição ao consciente, como marca essencial de estudos freudianos, em que se verifica que nada há de arbitrário nos acontecimentos psíquicos, por serem todos esses determinados, embora a diferença se expresse por não existir uma determinação única, mas que tem uma sintaxe na medida em que está livre do controle do consciente, dentro de limites possíveis, ao não permitir que a lógica se imponha ao relato, em que outra determinação se torna acessível, sendo essa a do insconscinente, de forma que esse possui uma ordem e estrutura tal como a linguagem (GARCIA-ROZA LA, 2009).

Nesse sentido, tendo em vista que o estudo do consciente implica uma complexidade que envolve tanto a história da filosofia como da psicanálise, especialmente, pela não univocidade do conceito de consciência, o que implica dizer que o objetivo deste artigo reside na tentativa de conceituar, expondo por perspectivas de diversos estudiosos, como estes apresentam os conceitos de consciente, inconsciente e consciente coletivo.

\section{REVISÃo BIBLIOGRÁFICA}

As habilidades de pensamento crítico envolvem a capacidade de diálogo com grandes filósofos acerca das teorias da natureza do comportamento humano, o que implica que uma análise aplicando perspectivas filosóficas, sociológicas e da psicanálise auxilia em identificação de elementos que podem explicitar perguntas, que também podem seguir por meio de uma visão psicológica, mas que pelas relações entre as teorias propiciam um exame crítico generalista (GOMES G, 2007). 
Prudente RCAC e Ribeiro MAC (2005), ao tratarem da construção de ciência, expõem que a filosofia tem como característica fundamental o estudo pelo amplo e universal, de forma um pouco diversa de outras ciências que se concentram em pontos em particular ou mais específicos, como parcelas de realidade, assim, tanto a filosofia como as ciências se encontram empenhadas em explicar causas e modos de expressão de certa realidade, embora a filosofia o faça por meio de análises mais globais, permitindo compreensão mais gradativa e articulada de temas considerados como mais complexos ou até mesmo controversos. Nesse sentido, a complexidade e a dispersividade dos conceitos que envolvem o consciente, o inconsciente e o consciente coletivo permitem justificar a opção por uma abordagem generalista mais interessada em demonstrar a problemática do tema sem privilegiar uma ou outra leitura psicanalítica ou filosófica, nem sociológica, discorrendo assim por vários autores e as perspectivas que estes apresentam (GOMES G, 2007).

Jung CG (1998) já expunha o uso de analogias para propiciar compreensão de conceitos, e seguindo por esse enfoque, é possível entender certos conceitos por meio de uma analogia simples da camisa e os seus botões, sendo essa uma posição que se aplica nesta exposição por propiciar, assim, mais fácil compreensão acerca dos conceitos a serem expostos. Entende-se a camisa como o inconsciente e como provável consciente os botões desta, seguindo o texto em direção do consciente que é subdividido em partes e em estados de consciência, regressando ao início de atividades cerebrais de leitura do ambiente e do julgamento da consciência, que implica processar informações e definir por meio destas o que se quer.

Damasceno MH (2005), em seu artigo, A Perspectiva Filosófica sobre o consciente, explica que esse se relacionava com a Filosofia da Consciência, como ideologia, e esta perspectiva em entendimento de Freud, com a perspectiva da psicanálise, deveria ser afastada do problema que surge em questão do pensamento, de forma que se percebe que a visão filosófica da consciência desconsidera os eventos que levam ao pensamento, ou seja, ao consciente. Nesse sentido, as contradições filosóficas propiciam uma adequação em reflexão com uma consciência única, por se considerar o consciente e o psíquico como idênticos e não possível representar o inconsciente psíquico (DAMASCENO MH, 2005).

Freud tem sido considerado como o pai da psicanálise e se centra em estudos que envolvem o inconsciente, relacionando este aos impulsos e instintos, mas não aceitando que o indivíduo fosse controlado por forças internas, uma vez que este estudioso entendia o inconsciente como pessoal, de forma que havia uma individualidade psíquica, na qual cada ser humano envolve os seus próprios conteúdos reprimidos, geralmente, entendendo estes como marcas da infância que abalam o equilíbrio da consciência (DAMASCENO MH, 2005).

No início dos estudos sobre consciente e inconsciente e consciente coletivo, a psicanálise surge como fundamento em face da extensão e da importância que atribui ao inconsciente e, na atualidade, este aspecto que envolve entender uma atividade psíquica inconsciente não proporciona surpresa por implicar 0 reconhecimento da importância das relações e transições que ocorrem entre processos inconscientes e conscientes, propiciando maior amplitude para análise de como se percebe e concebe a consciência (GOMES G, 2003). Gomes G (2003), dentro deste enfoque, expressa que as atividades de um ser humano, em tese, são referências dos sentidos e do ambiente em que o ser se insere, sendo fundamentadas em singelas transformações destes dois aspectos, expondo ainda que a psicanálise, proposta por Freud, implica o conteúdo da consciência que é marcado pela influência do inconsciente.

Assim, ao se discorrer sobre o entendimento de consciência tendo como base a perspectiva de Freud, explica-se que mesmo perante ambiguidades, a consciência surge como um órgão sensorial que propicia detecção de qualidades psíquicas e de processos de pensamento, e mesmo que Freud a tenha exposto como algo inexplicável e indescritível, o fez no âmbito da consciência da primeira pessoa em perspectiva desta, em aspecto de estar consciente de como este pensamento ocorre e se apresenta para a própria consciência, em sua experiência íntima, na análise do estar consciente como um dado sobre si mesmo (GOMES G, 2003).

Damascento MH (2005) expõe que o entendimento que se verifica na perspectiva de Freud em existir impenetrabilidade da consciência, em âmbito da primeira pessoa, não é algo a ser ignorado, em face da teoria se direcionar para uma clínica do inconsciente, visto que a psicanálise não se ocupa com a consciência, mas

REAS/EJCH | Vol.11(17) | e1538 | DOI: https://doi.org/10.25248/reas.e1538.2019 Página 3 de 7 
em representações e processos inconscientes da pessoa que podem ser inferidos do que o ser tem de consciência em escolhas que faz. Nesse sentido se verifica que, em algumas passagens, Freud atribui ao inconsciente essa propriedade de escolha que implica, em um raciocínio lógico, no questionamento acerca de como algo que não se tem consciente pode fazer escolhas, entretanto, o uso do termo parece ser mais uma dificuldade de lidar com a definição do conceito, do que um uso sistemático do mesmo.

Dessa perspectiva e pondo-se em uma situação hipotética e individual, a consciência individual é baseada nos sentidos e no ambiente, basicamente, como consciência de sobrevivência, por meio do instinto, podendo ser percebida como nata, por ser nascido do ambiente e, dessas primeiras interações do homem com o seu ambiente surge a consciência que serve para a sobrevivência, percebida como consciência individual, que decorre do ser menor para o maior indivíduo em um grupo (IBERTIS C, 2005). No entanto, conforme exposição de Gomes G (2003) acerca do entendimento de consciência que Freud apresenta, entende-se que a consciência não se aplica unicamente à percepção do ser, mas também com desejos e fantasias, bem como o pensamento em um processo que ocorre dentro de um sistema considerado como psicológico envolvido pelo ser fisiológico.

Assim, a consciência que uma pessoa tem de seus próprios processos de pensamentos, de sentimentos decorre de uma forma de percepção do seu conteúdo e do que está ao seu redor de maneira que se pode expor uma comparação de sobrevivência consciente do amor inconsciente, visto que certos sentimentos, como: amor e saudade apenas podem ser concebidos como obras do inconsciente em face das relações humanas, dependendo de situações que se sobrepõem uma a outra, mas que acabam por envolver o sistema mental ou psíquico em complementarem-se (LOPARIC Z, 2001).

Loparic Z (2001) explica com foco nesta perspectiva, que a percepção humana impulsiona e é impulsionada por formas de sentir sensoriais, bem como imaginativas, em uma relação que se constrói em processos dentro da mente de um indivíduo em composição de todo um sistema que é complexo em face de ser capaz, tanto de perceber o concreto como de gerar o abstrato, ou seja, a consciência é tão complexa que pode gerar fatos para sustentar um julgamento que traga satisfação pessoal ou ao grupo no qual o indivíduo se insere.

Com foco nesta visão, a percepção do inconsciente como primeiro fator de um indivíduo e em como forma sua consciência decorre de entender que esta consciência sustenta os julgamentos que este indivíduo realiza, de maneira que a percepção do inconsciente se torna consciente por estímulos e por meio destes, em situações e combinações de situações, decorre uma resposta consciente (LOPARIC Z, 2001)..

Em uma sequência de perspectiva, o artigo de Gomes G (2003) explicita que da mesma forma que Freud entende a relação de inconsciente com consciência, se aplica a prevalência de processos inconscientes sobre a consciência considerada empírica nos estudos de Kant, cujo entendimento envolve o aspecto de que a consciência empírica decorre do imediato, sendo assim vinculada com a linearidade do tempo, propiciando uma convergência de entendimento em perspectiva genética, que sucede a consciência empírica, de forma que há uma junção de pensamentos que funda o consciente que por sua natureza também é o inconsciente.

Ao tratar a relação de Freud com Kant, a consciência do indivíduo de seus processos mentais é a mesma que faz ao assimilar a forma de percepção, assim, ocorre um processo psíquico consciente de maneira que tal compreensão aproxima a concepção destes dois estudiosos, uma vez que segundo Kant os estados mentais podem ser conhecidos em si, como aparecem em senso interno (GOMES G, 2003) Em uma sequência de entendimento diverso, encontra-se nos estudos de Jung CG (1998), que a consciência individual decorre de um imenso processo de interpretações e estas podem ser próprias de cada indivíduo ou da coletividade, que para esse estudioso envolvia a representação da cultura do povo.

Assim, o inconsciente para Jung CG (1998) é caraterizado por duas camadas, sendo uma pessoal, por meio da qual se mantém toda a experiência de um indivíduo e esta pode ser reprimida, esquecida ou ignorada, embora haja situações que não são percebidas como relevantes e nem chegam à consciência. A outra camada que Jung CG (1998) apresenta envolve o que denomina de inconsciente coletivo, que decorre de uma área mais profunda no ser, em que estão contidos os instintos ao lado de imagens que são herdadas da 
humanidade, entendendo que os seres humanos herdam além de aspectos genéticos, aspectos que são por meio do tempo transformados juntamente com ideias, tecnologias e inovações que mesmo evoluindo não perdem a essência.

A consciência do indivíduo e sua posição no mundo propicia a construção de bases de sustentação em avaliar os seres da mesma espécie, observando nestes os mesmos motivos e costumes que geram a noção de liberdade ou de eliminar as bases da consciência (DAMASCENO MH, 2005). Nessa linha, depara-se com a noção sociológica de Durkheim E (1999) que pretende demonstrar que os fatos sociais têm existência própria e independente do que faz ou pensa cada indivíduo em particular, mesmo que todos apresentem uma consciência individual, o seu modo de se comportar e interpretar a vida representa formas de condutas ou de pensamentos que refletem um grupo ou sociedade.

Nessa linha, depara-se com a noção sociológica de Durkheim E (1999) que pretende demonstrar que os fatos sociais têm existência própria e independente do que faz ou pensa cada indivíduo em particular, mesmo que todos apresentem uma consciência individual, o seu modo de se comportar e interpretar a vida representa formas de condutas ou de pensamentos que refletem um grupo ou sociedade.

Dentro deste enfoque, Durkheim E (1999) apresenta a concepção de consciência coletiva, entendida como conjunto de crenças e de sentimentos comuns expressos por membros de uma mesma sociedade, que forma um sistema determinado que tenha vida própria. Entretanto, para que essa consciência se manifeste é importante que vários indivíduos tenham suas ações em combinação de um produto que replique formas coletivas de agir e de pensar, sendo estas manifestadas em uma realidade externa, ou seja, esta consciência coletiva não depende de um indivíduo ou de outro.

Nesse aspecto, se existe um inconsciente coletivo, existe também um consciente coletivo que decorre de bases de senso comum, aliás, sendo este senso comum o que norteia a maioria das decisões que 0 consciente coletivo expressa em julgamento e, muitas vezes, amadurecimento de uma reflexão profunda que delineia ou norteia a reflexão imediata, de forma que as propriedades do aparelho psíquico, segundo expressa Casanave CMIL (2008), implicam conservar o que anteriormente havia recebido para se manter onstantemente receptivo, propiciando a distinção entre representação e percepção que se aliam a noção de consciente e de inconsciente. Dentro desta perspectiva, o inconsciente coletivo complementa o inconsciente pessoal, manifestando-se também em uma percepção individual que pode ocorrer em sonhos, ou mesmo em construção de imagens e de símbolos, sendo este enfoque proposto por Jung CG (1998), como arquétipos, que também originam os mitos como produção de um coletivo.

Assim, na perspectiva jungiana, o inconsciente coletivo é algo que foi e está sendo elaborado, de forma contínua, por meio de experiências que são individualmente construídas em acesso às informações contidas no próprio consciente coletivo como forma de explicar o mecanismo de operação de fenômenos psíquicos, que são considerados desde o princípio da psicologia de Jung.

Assim, este aspecto surge como fato relevante ao alimentar a base de julgamento da consciência de um indivíduo, visto que sem este aspecto não se teria o amor, a saudade, a vingança, que são sentimentos que evoluíram baseados no sentido do ser e de se sentir inferiorizado e menosprezado, ou ainda, se sentir fora de um grupo e enganado, como se sentido estar sendo julgado, o que propicia alimentar a consciência de acordo com comportamento social e regras, que são construídas por estas sociedades que acabam por nortear o consciente coletivo (AUGUSTO LM, 2013).

De acordo com Durkheim E (2010), a consciência coletiva ou comum pode ser entendida como conjunto de crenças e de sentimentos comuns para os membros de uma mesma sociedade, e esse conjunto forma um sistema que ganha vida própria, sendo assim denominado de consciência coletiva ou comum. Essa consciência coletiva é difusa por definição ao ser estendida para toda sociedade, embora tal consciência possa ter características específicas propiciando assim uma realidade distinta, por ser independente de condições particulares dos indivíduos, o que faz com que se diferenciem as consciências particulares, uma vez que a consciência coletiva perpassa todos os indivíduos de uma sociedade, que têm propriedades e 
condiçôes de existência em seu modo de desenvolvimento, do mesmo modo que os aspectos individuais, mas de outra maneira.

Assim, a tomada de consciência se relaciona com aspectos que envolvem o ser e seu relacionamento com o seu ambiente, propiciando entender que a filosofia da mente contemporânea esteja marcada por muitas reflexes, que implicam perspectivas diversas sobre a consciência que envolve o mundo interior, bem como o que se apresenta para o próprio indivíduo e o ambiente em que se insere, em exposição da percepção da consciência em se sentir envolvido com o seu ambiente, tomando como base para este enfoque a teoria de Fromm E (1983) (SILVA JA et al., 2004).

Silva JÁ et al (2004) complementam que é importante ressaltar que cada enfoque teórico relacionado com aspectos psicológicos enuncia uma definição de personalidade por meio de modelos próprios, de forma que a teoria de Erich Fromm segue uma abordagem fundamentada na filosofia humanista, por meio da qual o ser humano precisa alcançar a sua verdadeira autonomia.

Dessa forma, o indivíduo se une a outros como meio que propicia regular a solidão de sua existência, uma vez que ocorre um sentimento de ligação de um ser em relação aos outros, sendo esta a razão pela qual Fromm E (1983) explica que o relacionamento humano é considerado não apenas como necessidade, mas como premissa para que se alcance saúde em face dos sentimentos e consciência pessoal.

Segundo exposição de Bezerra V (2010), em seu artigo, para Fromm E (1983), o indivíduo precisa se sentir envolvido em um grupo, tendo em vista que entre todos os animais, o ser humano é o único que capaz de estar ou se sentir isolado, porque se separa da natureza ou mesmo de outros indivíduos.

Os estudos de Fromm E (1983) seguem a perspectiva de Freud da condição do ser humano em estabelecer uma relação de dependência entre a natureza e os homens em sua vida finita, como condição de precariedade, constituindo-se uma tensão que envolve aspectos libidinosos, bem como da energia de preservação da espécie em um sofrimento que busca libertação pelo prazer, que segundo Bezerra $V(2010)$, explica o direcionamento de Fromm E (1983) em tratar as questões amorosas.

Por outro aspecto, a perspectiva deste teórico evidencia uma estrutura de sociedade moderna que afeta o ser humano o fazendo ficar mais independente e confiante, mas ao mesmo tempo, mais crítico, isolado e com medo. De acordo com exposição de Bezerra V (2010), a esta condição do ser humano, Fromm expõe como desamparo causado pela separação do homem da natureza, e desta condição se pressupõe que a necessidade humana se centra em conseguir a consciência de integridade e de individualidade, que pode ser expressa pelo amor, sendo este compreendido como a natureza produtiva do ser.

Nesse sentido, o ser humano precisa, de forma consciente, se sentir envolvido e atender suas necessidades. Bezerra V (2010, p. 65) explica que Fromm E (1983) expressa que as necessidades humanas são resultantes de suas condições de existência, expondo cinco aspectos que implicam a necessidade que esse ser tem de ser relacionar, de criar e de se arraigar, bem como a necessidade que decorre de construção de uma identidade aliada com a necessidade de estrutura de orientação e de vinculação.

Estas necessidades podem ser associadas com o fato de que o indivíduo busca conscientemente se inserir em um grupo, tal como já exposto anteriormente, demonstrando que há uma reprodução da existência social, que permite entender que o ser humano precisa se sentir "consciente" de sua condição em apreensão dos fundamentos que o fazem presente em um grupo, ao mesmo tempo em que procura de forma prática a mudança (BEZERRA V, 2010). Dessa forma, em uma retomada do que já se expôs anteriormente acerca da percepção humana que constrói processos dentro da mente de um indivíduo, esta relação compõe um sistema complexo que percebe o concreto como o abstrato, mas que gera fatos em posicionamento do indivíduo com ele mesmo e com o ambiente e o grupo no qual se insere.

\section{CONSIDERAÇÕES FINAIS}

Assim, o que se pode concluir é que muitos pensam ter consciência de si com liberdade de pensar ou agir e sentir, mas dentro de uma sociedade acabam tendo pensamentos, sentimentos e ações que são reflexos 
da vontade de um grupo, o que implica recuperar a noção de que podem ser apenas mais botões em uma camisa.

\section{REFERÊNCIAS}

1. AUGUSTO LM. Freud, Jung, Lacan: Sobre o Inconsciente. Porto: U. Porto Editorial, 2013. ISBN 978-989-746029-6;

2. BEZERRA V. Erich Fromm e a arte de amar. Revista Espaço Acadêmico no 110. Julho de 2010. p.62-68.

3. CASANAVE CMIL. As tramas de Mnemosine: a memória nos primórdios da teoria freudiana. Campinas, São Paulo, 2008.

4. DAMASCENO MH. A noção de não consciente dos filósofos e o inconsciente freudiano. Revista Mal-Estar e Subjetividade v. 5. № 1. Fortaleza, mar. 2005. Versão On-line ISSN 2175-3644.

5. DURKHEIM E. Da divisão do trabalho social. WMF Martins Fontes, São Paulo, 2010.

6. DURKHEIM E. As regras do método sociológico. 2. ed. São Paulo: Martins Fontes, 1999.

7. FROMM E. O medo à liberdade. Rio de Janeiro: Guanabara Koogan, 1983.

8. GABBI JUNIOR O. A teoria do inconsciente como teoria da memória. Psicologia USP, v. 4, n. 1-2, p. 247-260, 1 jan. 1993.

9. GARCIA-ROZA LA. 1936- Freud e o inconsciente. 24. ed. Rio de Janeiro: Zahar, 2009.

10. GOMES G. Teoria Freudiana da Consciência. Revista Psicologia: Teoria e Pesquisa. Maio-Ago. 2003. Vol. 19. N. 2, pp. 117-125.

11. IBERTIS C. Representação e traço mnêmico no texto Freudiano sobre as afasias. Revista de Filosofia, Curitiba, v. 17 n. 20, p. $11-23$, jan.jun. 2005.

12. JUNG CG. A dinâmica do Inconsciente. 3 ed. Petrópolis: Ed. Vozes, 1998.

13. LOPARIC, Z. Além do inconsciente: sobre a desconstrução heideggeriana da psicanálise. Natureza Humana 3(1): 91-140, jan.-jun. 2001.

14. LOPARIC Z. Theodor Lipps: uma fonte esquecida do paradigma freudiano. Nat. hum., São Paulo, v. 3, n. 2, p. 315-331, dez. 2001.

15. PRUDENTE, RCAC; RIBEIRO, MAC. Psicanálise e ciência. Psicol. cienc. prof., Brasília, v. 25, n. 1, p. 58-69, Mar. 2005.

16. SILVA JÁ, et al. Erich Fromm: uma teoria da personalidade baseada na segurança em detrimento à liberdade. 